\title{
Is Health Locus of Control a Modifying Factor in the Health Belief Model for Prediction of Breast Self-Examination?
}

\author{
Rahim Tahmasebi ${ }^{1,2}$, Azita Noroozi ${ }^{3 *}$
}

\begin{abstract}
Background: Breast cancer is one of the most common cancers among women in the world. Early detection is necessary to improve outcomes and decrease related costs. The aim of this study was to assess the predictive power of health locus of control as a modifying factor in the Health Belief Model (HBM) for prediction of breast self-examination. Materials and Methods: In this cross- sectional study, 400 women selected through the convenience sampling from health centers. Data were collected using part of the Champion's HBM scale (CHBMS), the Health Locus of Control Scale and a self administered questionnaire. For data analysis by SPSS the independent $T$ test, Chi square test, logistic and linear regression modes were appliedl. Results: The results showed that $10.9 \%$ of the participants reported performing BSE regularly. Health locus of control did not act as a predictor of BSE as a modifying factor. In this study, perceived self-efficacy was the strongest predictor of BSE performance $(\operatorname{Exp}(B)=1.863)$ with direct effect, while awareness had direct and indirect influence. Conclusions: For increasing BSE, improvement of self-efficacy especially in young women and increasing knowledge about cancer is necessary.
\end{abstract}

Keywords: Breast cancer - breast self examination - Health Belief Model - health locus of control

Asian Pac J Cancer Prev, 17 (4), 2229-2233

\section{Introduction}

Breast cancer is the most common cancer among women worldwide (Yan Yee., 2009). In Iran, breast cancer is also the most common cancer among women and includes $21.4 \%$ of all malignancies in women (Noroozi et al., 2011). This problem, due to disability and premature death, can impose a burden to society. Breast cancer is a stressful experience that coincides with a significant relationship between the levels of emotional distress and loss of daily function.

Early diagnosis plays an essential role in reducing mortality from breast cancer. Strategies for early detection of breast cancer in women, include performing breast self examination (BSE), clinical examination or mammography. Since breast self-examination has a critical role in the diagnosis of disease, it is important that women constantly do this as a professional behavior. But unfortunately, despite the benefits of regular breast selfexamination, only a small number of women are engaged in this action (Petro-Nustus et al., 2002). Therefore, it is necessary to identify the factors influencing in BSE.

Effectiveness of training programs and identifying factors influencing unhealthy behavior changes greatly depends on the proper use of theories and models used in health education. Health Belief Model (HBM) is a cognitive model that can be used to identify the factors influencing screening behavior (Noroozi et al., 2011; Tastan et al., 2011). According to this model, behavioral belief along with modifying factors is effective in shaping behavior. Behavioral belief includes constructs such as perceived susceptibility, perceived severity, perceived benefits and barriers, health motivation and self-efficacy (Canbulat et al., 2008). Modifying factors include demographic variables, personality traits and individual awareness that can play a role in shaping behavior in the direct or indirect (through Behavioral belief) ways.

However, screening behaviors is under the individual control and whether it is done or not can be linked to the locus control. The concept of Health Locus of Control is an important factor in the perceived control in the individuals' health behavior. Health Locus of Control has been derived by Rotter from social learning theory. Based on this construct, the individual perceptions of life events may be attributed to the internal, external and chance factors. People with internal Locus of Control believe that their actions determine the consequences and outcomes of their health, those who have external Locus of Control believe that other powers such as doctors, nurses or family members determine their health, and people with chance Locus of Control think that their health is determined by fate, luck and chance (Rowe et al., 2005). In other words, to explain the behavior, Rotter considers both strengthening the external and the internal cognitive

${ }^{1,2}$ Department of Health and the Persian Gulf Marine Biotechnology Research Center, Bushehr University of Medical Sciences, Bushehr, Iran *For correspondence: azitanoroozi@ gmail.com 
processes (Schultz et al., 2005). So it seems that the Health Locus of Control as a modifying factor (similar personality traits) can play an important role in shaping behavior.

In the field of the relationship between the Health Locus of Control and performance of health behavior, we can refer to Rowe's study on the relationship between the Health Locus of Control and perceived risk for breast cancer in healthy women. In this study it was found that there is a significant relationship between the internal locus of control and perceived risk for breast cancer (Rowe et al., 2005). In another study that was conducted to investigate the relationship of breast self-examination and the Health Locus of Control, it was concluded that there is a relationship between breast self-examination and the internal locus of health control, but there is no significant relationship between external and chance locus of control and breast self-examination behavior. In such a way that in one study, self-efficacy and perceived susceptibility construct were a strong predictor for performing breast self-examination and in other study, severity and perceived barriers were stronger predictors (Hallal., 1982; Cheryl et al., 1999; Schultz et al., 2005; Noroozi et al., 2011).

However, so far, no study has been conducted with the combination of the HBM and the Health Locus of Control constructs to predictive the power of health locus of control as modifying factor in Health Belief Model. Also there are some disagreements on the effective constructs of HBM. So aim of this study is recognition of predictor power of health locus of control as a modifying factor in Health Belief Model (HBM) for prediction of breast self-examination, so that it can be used to design effective educational programs.

\section{Materials and Methods}

This cross sectional study was accomplished on

Table 1. Relationships between Quantitative Modifying Factors and BSE Performance

\begin{tabular}{lccc}
\hline \multirow{2}{*}{$\begin{array}{c}\text { Quantitative } \\
\text { modifying } \\
\text { factors }\end{array}$} & BSE Yes & BSE No & \\
\cline { 2 - 3 } & Mean \pm SD & Mean \pm SD & P Value \\
\hline Age & $30.90 \pm 8.08$ & $29.74 \pm 8.16$ & 0.174 \\
Awareness & $6.11 \pm 3.50$ & $4.04 \pm 3.14$ & $<0.001$ \\
Internal HLOC & $28.01 \pm 4.53$ & $28.31 \pm 5.75$ & 0.705 \\
External HLOC & $25.80 \pm 5.08$ & $26.35 \pm 6.42$ & 0.357 \\
Chance HLOC & $18.97 \pm 5.61$ & $19.62 \pm 6.57$ & 0.309 \\
\hline
\end{tabular}

400 women aged 20 to 50 years, who were referred to health centers in Bushehr city (Iran). The sample size was determined based on determination coefficient of 0.4 and in a total of 12 variables in the regression model. The samples in this study were selected by convenience sampling, in a way that at first, five health centers out of 10 in Bushehr were selected randomly (by lottery), and the sample size in each center were determined based on the proportion of $20-50$ years women. Exclusion criteria for this study were the diagnosed breast cancer during the study, mental health problems, physical disabilities and illiteracy.

For data collection in this study, questionnaires were completed with self-report. Data collection instruments consist of three questionnaires includes: 1) self-administered questionnaire included the sociodemographic variables of the participants and breast self-examination behavior, 2) Champion's Health Belief Model Scale (42 questions) and awareness of cancer (15 items). the questions related to Champion Scale separately consists of 5 questions about perceived susceptibility (personal vulnerability), 7 questions on perceived severity (perceived depth of the risk and seriousness of the complications), 6 questions to measure perceived benefits (positive results from avoiding exposure to a disease), 6 questions about perceived barriers (barriers to behavior), 11 questions related to perceived self-efficacy (confidence in one's ability to successful behavior performance), and 7 questions about the health motivation (health-related beliefs and behaviors) that all were measured by 5-level Likert scale. Awareness questions had scores of 0 or 1 , and the range of 0-15, and 3) Multidimensional Health Locus of Control (Form B) Scale (MHLCS) with 18 questions which was measured internal, external and chance control of health with the same number of questions (6 questions for each dimension) and 6-level Likert scale.

Validity and reliability of Champion Scale for screening breast cancer behavior among Iranian women has been measured (Taymoori et al., 2009). This scale was reliable and the ranges of Cronbach's alpha coefficients were 0.75 (health motivation) to 0.94 (self-efficacy). Cronbach's alpha coefficient in awareness scale was 0.81 .

Validity and reliability of Multidimensional Health Locus of Control Scale have been assessed and approved (Wallston, 2007). In this study, Cronbach's alpha coefficient in MHLCS was 0.81 .

Prior data collection, aim of study was explained for samples and the participants were told that all information

Table 2. Relationships between Qualitative Modifying Factors and BSE Performance

\begin{tabular}{cccc}
\hline \multirow{2}{*}{ Qualitative modifying factors } & BSE Yes & BSE No \\
& No $(\%)$ & No $(\%)$ \\
\hline \multirow{2}{*}{ Education } & Under diploma & $44(37.3 \%)$ & $70(62.7 \%)$ \\
& Diploma & $50(41.8 \%)$ & $65(58.2 \%)$ \\
college degree & $80(57.1 \%)$ & $58(42.9 \%)$ & $188(54 \%)$ \\
Marriage & Yes & $160(46 \%)$ & $19(61.3 \%)$ \\
& Single & $12(38.7 \%)$ & $22(46.8 \%)$ \\
Family history & Yes & $25(53.2 \%)$ & $183(55.1 \%)$ \\
\hline
\end{tabular}


would be kept secret and anonymous.

The data obtained from the total of 400 completed questionnaires for BSE performance were coded and entered into the statistical package for social sciences (SPSS) version 18.0. Descriptive statistics were used to examine the characteristics of the sample. Then the participants were divided into two groups. BSE group 1 , the women aged 20 years and older who reported to perform BSE and group 2, the women with the same age who did not perform BSE. Differences between the two groups were assessed by t-test and chi square test. Logistic regression analysis was conducted to assess the direct effects of HBM constructs and modifying factors (demographic variables, awareness and three dimensions of health locus of control) on BSE performance. Then linear regression model was conducted to assess the indirect effects of modifying factors in effective construct or constructs (defined in the logistic regression model) as a dependent variable. In all tests, the level of significance was 0.05 .

\section{Results}

Overall, 400 women aged 20 to 50 years with a mean age of $8.08 \pm 27.30$ participated in this study. In terms of education, $22.6 \%(n=88)$ have been educated under diploma, $41.3 \%(n=161)$ were graduated from high school, and $36.2 \%$ participants $(n=141)$ had obtained college degree. Most participants $(n=358,91.3 \%)$ were

Table 3. Relationships between CHBMS Subscales and BSE Performance

\begin{tabular}{|c|c|c|c|}
\hline \multirow{2}{*}{ CHBMS subscales } & BSE Yes & BSE No & \multirow{2}{*}{ P Value } \\
\hline & Mean \pm SD & Mean \pm SD & \\
\hline Perceived susceptibility & $2.11 \pm 0.86$ & $2.16 \pm 0.93$ & 0.537 \\
\hline Perceived seriousness & $3.35 \pm 0.95$ & $3.55 \pm 1.07$ & 0.061 \\
\hline Perceived benefits & $4.21 \pm 0.72$ & $3.99 \pm 0.89$ & 0.009 \\
\hline Perceived barriers & $1.88 \pm 0.69$ & $2.07 \pm 0.40$ & 0.014 \\
\hline Perceived self-efficacy & $3.56 \pm 0.74$ & $3.01 \pm 1.00$ & $<0.001$ \\
\hline Health motivation & $4.28 \pm 0.50$ & $4.24 \pm 0.58$ & 0.412 \\
\hline
\end{tabular}

married. Concerning their awareness, $35.8 \%$ participants $(n=143)$ had no knowledge about cancer and had not used any source, $12.2 \%$ participants $(n=49)$ had acquired their knowledge from the health providers, $11 \%(n=44)$ from books, $4.2 \%(n=17)$ from friends, $15.5 \%(n=62)$ from mass media, and $8.1 \%$ participants $(n=32)$ had used several sources. $9 \%$ patients $(n=36)$ had other sources and $4.2 \%(n=17)$ participants did not report any source for their knowledge. A family history of breast cancer was reported by $12 \%(n=48)$ of the participants. Regarding the signs and symptoms of breast cancer, $14.2 \%$ participants $(n=57)$ reported some symptoms of cancer.

In this study, $45.9 \%$ women $(n=177)$ was performed BSE, but only $10.9 \%$ women $(n=42)$ stated that they performed BSE on a regular monthly basis. Quantitative modifying factors (three dimensions of health locus control, age, and awareness) are statistically compared in Table1, and qualitative modifying factors (education, marriage, and family history) are shown in Table 2. BSE performance was significantly related to attending school for college degree, and having knowledge. No significant associations were identified between performing BSE with three dimensions of health locus of control and other variables.

The CHBMS components of the two BSE groups have been presented in Table 3. Significant differences between the two groups were observed for the subscales of benefits ( $p=0.00)$, barriers ( $p=0.01)$, and self-efficacy $(\mathrm{p}=0.00)$.

Logistic regression analysis was used to assess predictor power of three dimensions of health locus of control, other modifying factors, and CHBMS components for performing BSE. In the logistic regression analysis, three dimensions of health locus of control didn't have direct effect in BSE. Perceived self-efficacy and awareness had significant odds ratios. The results revealed that the women with greater perceived self-efficacy were almost two time more likely to perform BSE than those with lower perceived self-efficacy $(\mathrm{OR}=1.86)$, and the women with greater knowledge were one time more likely to perform BSE than those with lower perceived self-efficacy $(\mathrm{OR}=1.13)$. The amounts of regression coefficients and

Table 4. Regression Coefficients and Odds Ratio in Logistic Regression for BSE performance

\begin{tabular}{|c|c|c|c|c|c|}
\hline \multicolumn{3}{|c|}{ Variables/ constructs } & $\mathrm{B}$ & $\operatorname{Exp}(B)$ & P Value \\
\hline \multirow{6}{*}{ Constructs } & & Perceived susceptibility & 0.065 & 1.067 & 0.637 \\
\hline & & Perceived seriousness & -0.239 & 0.787 & 0.055 \\
\hline & & Perceived benefits & 0.078 & 1.081 & 0.635 \\
\hline & & Perceived barriers & -0.248 & 0.781 & 0.149 \\
\hline & & Perceived self-efficacy & 0.622 & 1.863 & 0 \\
\hline & & Health motivation & -0.15 & 0.861 & 0.534 \\
\hline \multirow{9}{*}{ Modifying factors } & & Internal HLOC & -0.034 & 0.967 & 0.244 \\
\hline & & External HLOC & -0.007 & 0.944 & 0.812 \\
\hline & & Chance HLOC & 0.013 & 1.013 & 0.568 \\
\hline & & awareness & 0.125 & 1.133 & 0.001 \\
\hline & & age & -0.002 & 0.998 & 0.889 \\
\hline & \multirow{4}{*}{ Education } & Marriage & -0.519 & 0.595 & 0.261 \\
\hline & & Diploma/under diploma & -0.149 & 0.862 & 0.66 \\
\hline & & College degree/under diploma & 0.117 & 1.124 & 0.757 \\
\hline & & Family history & -0.479 & 0.62 & 0.198 \\
\hline
\end{tabular}


significance level of constructs and variables have been presented in Table 4.

Perceived self-efficacy was only construct that affects the BSE, therefore linear regression model was used to assess the indirect predictors of performing BSE (by perceived self-efficacy) for three dimensions of health locus of control, and other modifying factors. Three dimensions of health locus of control didn't have indirect effect in BSE. Age $(p<0.001)$ and awareness $(p=0.001)$ were determinant factors of self-efficacy and had indirect effects on BSE. In this way, one unit change in age and awareness scores would increase the amount of perceived self-efficacy to 0.03 and 0.05 , respectively. Therefore perceived self-efficacy constructs directly, awareness variable both directly and indirectly, and age indirectly are considered as predictive factors for BSE.

\section{Discussion}

According to the findings, the frequency of regular BSE (monthly) among Iranian women who referred to health care centers has been very low, three dimensions of health locus of control didn't have direct and indirect effects in BSE, and awareness about cancer and the perceived self-efficacy are the most important factors affecting this behavior. In addition to the direct effect, awareness also has had indirect effect on BSE through self-efficacy.

The rate of performing regular BSE found here was nearly identical to that $(7 \%)$ of previous study conducted in the Jordanian women (Petro-Nustus et al., 2002), while the frequency of this behavior in a sample of Turkish women was $17 \%$ (Secginli et al.,), and it is reported to be $26.9 \%$ in Jewish Women and $22.3 \%$ in Arab Women (Cohen et al., 2005). Therefore, the rate of BSE among Iranian women is low and recognition of effective factors for improving behavior is necessary.

In this study, among the modifying factors, education level and awareness about cancer were significantly associated to BSE performance. However, only awareness was the predictor of BSE performance.

These results support previous findings in this regard suggesting that well-educated women are more likely to perform BSE (Bottorff et al., 1998; Straughan et al., 2000; Cohen et al., 2005; Sadler et al., 2007; Avci., 2008). Consistent to the findings of other studies (Han et al., 2000; Cohen et al., 2005; Erbay Dundar et al., 2006; Sadler et al., 2007), in the present work, awareness about breast cancer was found to be predictor of performing BSE in Iranian women. It has been revealed that as education level and awareness increase, self-reliance, self-respect and willingness to know one's own body increase as well (Avci, 2008). These findings also suggest the urgent need for increasing women's awareness to become familiar with the feel and appearance of their breasts, and to seek medical evaluation if they notice changes in their breasts.

In some studies, education was identified as a predictor of this behavior (Noroozi et al., 2011; Cohen et al., 2005; Avci., 2008) that is inconsistent with the present study. It could be due to the overlapping of this variable with awareness about cancer. In other word, since educated person have higher awareness, this predictor becomes stronger.

In the current study, age indirectly and through selfefficacy has influenced the BSE which is similar to the findings of many studies (Umhe et al., 2003; Secginli et al., 2006; Noroozi et al., 2011). In this study, there wasn't any significant correlation between the internal, external, and chance control with BSE. In several studies, there was no relationship between internal control and BSE (Hallal, 1982: Glenn et al., 1990), and there was a negative correlation between external control and BSE (Hallal, 1982). But in a study conducted by Pierre Angel on African-American women, there was a correlation between the internal control and BSE, and there wasn't any correlation between external and chance control with BSE performance. In a recent study, the mean scores of internal, external, and chance control were very similar, and there were not a person with highly internal or external control. Thus lack of relation could be due to this fact, therefore further study in this area is necessary.

Consistent to the findings of other studies, a family history of cancer (Noroozi et al., 2011; Cohen et al., 2005; Andersen et al., 2003; Hackshaw et al., 2003) was not associated with BSE. One explanation for these findings may be this fact that the most high risk women, consider breast cancer generally as a serious condition and uncontrollable, and didn't perform its.

Concerning the HBM, the women who performed BSE perceived higher benefits, self-efficacy, and also fewer barriers than those who did not perform BSE, and the perceived self-efficacy was considered as strong predictor of this behavior that is consistent with the results of numerous studies (Noroozi et al., 2011; Secginli et al., 2006; Avci., 2008; Umhe et al., 2003; Sadat Tavafians et al., 2009; Jirojwong et al., 2003). In other words, selfefficacy is considered as an important determinant of breast self-examination behavior.

The results of this study showed that the constructs of perceived benefits and perceived barriers were associated with BSE, but in current study unlike other studies, the constructs of perceived barriers (Cohen et al., 2005; Umhe et al., 2003), perceived benefits (Secginli et al., 2006; Cohen et al., 2005; Avci., 2008), perceived vulnerability (Secginli et al., 2006; Umhe et al., 2003), and health motivation (Secginli et al., 2006; Umhe et al., 2003) were not predictor of the behavior. Previous studies showed a contradiction concerning the relationship between these constructs and BSE that could be due to different culture. People with different cultures have different sensitivity and barriers for this behavior.

The limitations of this study are assessing breast self-examination as self-reports, in which people usually would report the behavior higher than the actual amount (Mc Caul et al., 1996). Furthermore, this study was based on a convenience sample, so that its findings of this study may not be generalized to all Iranian women. Overall, community-based programs should be expanded to different Iranian women groups to assess the actual rate of screening behaviors and effective factors on them.

Conclusion:

It can be concluded that in order to promote breast Self- 
examination behavior, it is necessary to consider training risk factors and prevention method of cancer. Furthermore, increasing self-efficacy of women through displaying educational films and practice on a model are required, and various techniques such as verbal persuasion, emotional stimulation, performance accomplishment, and modeling especially for young women who have less self-efficacy could be utilized in this important matter.

Since health locus of control was not a determinant factor, better results could be achieved by conducting more researches in this area, especially in samples with highly internal or external control. Therefore, more extensive research is required in this regard in different groups of women.

\section{Acknowledgements}

This study has been supported by the research deputy of the Bushehr University of Medical Sciences. The author of this paper declares that there are no conflicts of interest.

\section{References}

Andersen MR, Smith R, Meischke H, et al (2003). Breast cancer worry and mammography use by women with and without a family history in a population-based sample. Cancer Epidemiol Biomark Prev, 12, 314-20.

Avci IA (2008). Factors associated with breast self-examination practices and beliefs in female workers at a Muslim community. Eur J Oncol Nurs, 12, 127-33.

Bottorff JL, Johnson JL, Bhagat R, et al (1998). Beliefs related to breast health practices: the perceptions of South Asian women living in Canada. Soc Sci Med, 47, 2075-85.

Canbulat N, Uzun O (2008). Health beliefs and breast cancer screening behaviors among female health workers in Turkey. Eur J Oncol Nurs, 12, 148-56.

Cheryl JH, Deborah IF, John C (1999). Health beliefs, health locus of control, and women's mammography behavior. Cancer Nurs, 22, 149-56.

Cohen M, Azaiza F (2005). Early breast cancer detection practices, health beliefs, and cancer worries in Jewish and Arab women. Prev Med, 41, 852-8.

Erbay Dundar P, Ozmen D, Ozturk B, et al (2006). The knowledge and attitudes of breast self-examination and mammography in a group of women in a rural area in western Turkey. BMC Cancer, 6, 1-9.

Glenn BL, Moore LA (1990). Relationship of self-concept, health locus of control, and perceived cancer treatment options to the practice of breast self-examination. Cancer Nurs, 13, 361-5.

Hackshaw AK, Paul EA (2003). Breast self-examination and death from breast cancer: A meta-analysis. $\mathrm{Br} J$ Cancer, 88, 1047-53.

Hallal JC (1982). The relationship of health beliefs, health locus of control, and self concept to the practice of breast selfexamination in adult women. Nurs Res, 31, 137-42.

Han Y, Williams RD, Harrison RA (2000). Breast cancer screening knowledge, attitudes, and practices among Korean American women. Oncol Nurs Forum, 27, 1585-91.

Jirojwong S, Mac Lennan R (2003). Health beliefs, perceived self-efficacy, and breast self-examination among Thai migrants in Brisbane. J Adv Nurs, 41, 241-9.

Mc Caul KD, Branstetter AD, Schroeder DM, et al (1996). What is the relationship between breast cancer risk and mammography screening? A meta-analytic review. Health
Psychol, 15, 423-429.

Noroozi A, Tahmasebi R (2011). Factors influencing breast cancer screening behavior among Iranian women. Asian Pac J cancer Prev, 12, 1239-44.

Noroozi A, Jomand T, Tahmasebi R (2011). Determinants of breast cancer self examination performance among Iranian women: An application of the Health Belief Model. J Canc Educ, 26, 36574.

Petro-Nustus W, Mikhail BI (2002). Factors associated with breast self-examination among Jordanian women. Public Health Nurs, 19, 263-71.

Rowe JL, Montgomery GH, Duberstein PR, et al (2005). Health locus of control and perceived risk for breast cancer in healthy women. Behav Med, 31, 33-40.

Sadat Tavafians S, Hasani L, Aghamolaei T, et al (2009). Prediction of breast self examination in a sample of Iranian women: an application of the health belief model. $B M C$ Women Health, 9, 1-7.

Sadler GR, Ko CM, Cohn JA, et al (2007). Breast cancer knowledge, attitudes, and screening behaviors among African American women: the black cosmetologists promoting health program. BMC Public Health, 7, 1-8.

Schultz DP, Schultz ES (2005). Theories of personality. $8^{\text {th }}$ ed. United state: Thomson Wadsworth.

Secginli S, Nahcivan NO (2006). Factors associated with breast cancer screening behaviors in a sample of Turkish women: a questionnaire survey. Int J Nurs Stud, 43, 161-71.

Straughan PT, Seow A (2000). Attitudes as barriers in breast screening: a prospective study among Singapore women. Soc Sci Med, 51, 1695-703.

Tastan S, Iyigun E, Kilic A, et al (2011). Health beliefs concerning breast self examination of nurses in Turkey. Asian Nurs Res, 5, 151-6.

Taymoori P, Berry TR (2009). The validity and reliability of Champion's Health Belief Model Scale for breast cancer screening behaviours among Iranian women. Cancer Nurs, 32, 465-72.

Umhe K, Dimitrakaki V (2003). Breast cancer detection in asymptomatic women: Health beliefs implicated in secondary prevention. J Appl Behav Res, 8, 96-115.

Wallston KA (2007). Multidimensional Health Locus of Control (MHLC) Scale (Form B). http://www.nursing.vanderbilt. edu/faculty/kwallston/mhlcscales.htm.

Yan Yee Y (2009). Breast cancer: Knowledge perceptions of Chinese women in Hong Kong. GJHS, 1, 97-105. 